\title{
若尔盖高原泥炭沼泽湿地土壤细菌群落空间分布及其 驱动机制
}

\author{
王好才 ${ }^{1}$, 夏 敏 $^{1}$, 刘圣恩 ${ }^{2}$, 王 $\quad$ 炏 $^{3}$, 展鹏飞 ${ }^{4}$, 王 $\quad$ 行 $^{1, *}$ \\ 1 西南林业大学国家高原湿地研究中心/湿地学院, 昆明 650224 \\ 2 中国科学院沈阳应用生态研究所, 沈阳 110016 \\ 3 云南农业大学农学与生物技术学院, 昆明 650201 \\ 4 福建师范大学地理科学学院, 福州 350007
}

摘要:了解高原泥炭沼泽湿地生态系统土壤微生物群落结构组成、多样性及空间分布特征对认识高原湿地生态特征及演化过程 至关重要。利用高通量测序技术, 在局域尺度上研究了四川若尔盖高原泥炭沼泽湿地土壤细菌群落结构与多样性特征。通过 进一步测定土壤及植物基本理化指标,量化采样点之间的地理距离, 比较了细菌群落不同成员 (稀有种和丰富种) 的空间周转 差异,分析了土壤环境变量和空间因子对细菌群落结构的相对贡献。结果表明:若尔盖泥炭土壤细菌群落主要由绿弯菌门 (Chloroflexi) (26.25\%)、变形菌门(Proteobacteria) (23.21\%)、厚壁菌门(Firmicutes)(10.56\%)等优势物种门类组成; 土壤细菌群 落结构表现出较强的空间依赖关系, 群落结构相似性随采样点地理距离增加而逐渐降低,细菌群落的周转速率表现为总细菌群 落>丰富种>稀有种; Mantel 检验结果显示, 地上生物量与细菌群落呈极显著相关性 $(P<0.01)$, 其中, 影响稀有种空间分布特征 的环境因子还包括土壤硫含量、活性磷、 $\mathrm{Mn}$ 和土壤 $\mathrm{pH}$ 值; 方差分解分析表明,局域尺度上的土壤因子对若尔盖高原泥炭沼泽 土壤细菌群落构建的相对贡献大于空间因子,土壤异质性是影响微生物空间分布特征的关键因素。研究为开展高原湿地泥炭 土壤微生物多样性调查及揭示微生物群落构建机制提供了重要参考。

关键词: 土壤微生物; 高原湿地;微生物地理学;环境响应

\section{Spatial distribution and driving mechanism of soil bacterial communities in the wetland of Zoige plateau}

\author{
WANG Haocai ${ }^{1}$, XIA Min ${ }^{1}$, LIU Shengen ${ }^{2}$, WANG Yi ${ }^{3}$, ZHAN Pengfei ${ }^{4}$, WANG Hang ${ }^{1, *}$ \\ 1 National Plateau Wetlands Research Center/College of Wetlands, Southwest Forestry University, Kunming 650224, China \\ 2 Institute of Applied Ecology, Chinese Academy of Sciences, Shenyang 110016, China \\ 3 College of Agronomy and Biotechnology, Yunnan Agricultural University, Kunming 650201, China \\ 4 School of Geographical Sciences, Fujian Normal University, Fuzhou 350007, China
}

\begin{abstract}
Identifying the microbial community composition, diversity, and spatial distributional features in samples collected from the plateau peat wetlands is important to understand the ecological characteristics and evolutionary processes of plateau wetland ecosystems. In this study, by using high-throughput sequencing technology, we studied soil bacterial community composition and structure as well as bacterial diversity at the local scale of geographic spaces in the peat wetlands of Zoige Plateau, which are located in Sichuan province, China. The basic plant and soil properties were tested and the geographic distances between the pairwise sampling points were quantified. Additionally, the spatial turnover of the
\end{abstract}

基金项目:国家自然科学基金项目(41877346); 云南省应用基础研究计划项目(2019FB036);云南省“万人计划”项目(YNWR-QNBJ-2018-235)

收稿日期:2020-02-13; 网络出版日期:2021-01-27

*通讯作者 Corresponding author.E-mail: hwang17@163.com 
different members of bacterial communities (i.e., endemic taxa and ubiquitous taxa) was compared, and the relative contributions of the different environmental variables and spatial factors to the bacterial community composition and structure were analyzed. The results showed that Chloroflexi, Proteobacteria, and Firmicutes were the most dominant bacteria in the peat wetlands of Zoige Plateau, and the relative abundance of these dominant phyla was 26.25\%, 23.21\%, and 10.56\%, respectively. Soil bacterial community compositions were strongly related to the spatial distances. The composition similarity of bacterial communities gradually decreased with the increase in geographical distances between the pairwise sampling points, and bacterial community compositions showed a decreasing order in their spatial turnover rates as follows: the total bacterial community>ubiquitous community>endemic community. The results of Mantel test analysis showed that the aboveground biomass exerted the most significant effect on the bacterial community composition and structure $(P<0.01)$; meanwhile, soil sulfur content, soil active phosphorus content, soil manganese content, as well as soil $\mathrm{pH}$ also affected the spatial distribution of endemic taxa. Variation partition analysis showed that, at the local scale of geographic spaces, edaphic factors played more important role than spatial factors in shaping the composition and structure of soil bacterial communities in the peat wetlands of Zoige Plateau. Especially, soil heterogeneity was the key factor that affected the spatial distributions of soil microbial communities. The present work provides an important reference for investigating soil microbial diversity in the plateau peat wetlands and also provides a theoretical basis for revealing the mechanisms of microbial community assembles over geographic spaces in the plateau wetlands.

Key Words : soil microbe; plateau wetland; micro-geography; environmental response

湿地生态系统是地球上最重要的生态系统之一, 在物质循环、能量流动、维持生态平衡等方面发挥着重要 的生态价值和环境功能 ${ }^{[1-3]}$ 。微生物是湿地生态系统的重要组成部分, 是土壤有机质与土壤养分转化与循环 的动力, 开展湿地土壤微生物相关研究对于认识和了解湿地生态系统生境状况与演化具有重要意义 ${ }^{[4-6]}$ 。我 国的高原湿地主要分布在海拔 $3000 \mathrm{~m}$ 以上的高原区域, 是一类特殊的湿地类型。受气候变化及人为活动干 扰, 高原湿地生物组成及区系特征对环境变化异常敏感, 其土壤微生物群落多样性和分布状况受土壤质地、植 被类型、土壤 $\mathrm{pH}$ 及水分状况等因素影响 ${ }^{[7]}$ 。因此, 在全球气候变化背景下, 开展高原湿地土壤微生物多样性 及其空间分布研究,对进一步辨析湿地关键生态特征及其演化过程具有重要意义 ${ }^{[8]}$ 。

土壤微生物具有明显的地域性特征, 表现出一定的空间分布关系 ${ }^{[9]}$ 。当前, 土壤微生物群落结构相似性 和地理空间距离的响应关系在草地、农田、森林等生境中已被证实 ${ }^{[10-12]}$ 。在湿地生态系统中, 有关土壤微生 物空间分布特征的研究主要集中在人工湿地。如有研究表明,在受人类干扰较大的人工湿地类型(如库塘、 水稻田等) 中存在微生物群落相似性随地理距离增加而衰减的一般规律 ${ }^{[13-14]}$ 。在自然湿地生态系统中, 尤其 是原始生境保存较好的高原泥炭沼泽湿地, 土壤微生物群落相似性对地理距离的响应关系仍然未知。环境因 素显著影响微生物群落组成和分布, 微生物一环境之间存在密切的相互作用关系 ${ }^{[15-17]}$ 。空间尺度大小对土 壤微生物不同成员在群落构建方面的潜在驱动因素还尚不明确。在土壤微生物群落中, 稀有种被定义为在不 同样品间占据率较低的微生物, 而丰富种是指在大量样品中普遍存在且丰度较高的类群 ${ }^{[18]}$ 。在气候变化、群 落组装过程及环境适应方面, 稀有种和丰富种的响应机制表现出明显的差异 ${ }^{[19-21]}$, 而在以往的微生物地理学 研究中, 往往会把所有微生物群落作为一个整体来探究其生物地理分布模式, 少有将群落按照丰度高低划分 为稀有种和丰富种, 并分别加以研究。由此我们提出假设: 在自然湿地生态系统中, 微生物群落不同成员的生 物地理分布模式可能存在明显的差异。

由于若尔盖高原泥炭沼泽湿地在碳存储方面的重要性, 人们在全球变暖、水文波动环境下的土壤微生物 活性及多样性变化方面开展了大量研究工作 ${ }^{[22-23]}$ 。目前, 对若尔盖高原湿地土壤微生物的研究侧重于生境 退化和扰动对微生物多样性及结构的影响, 以及泥炭层中有机物的微生物利用特征等方面, 而土壤微生物生 物地理分布模式尚不明确 ${ }^{[24-26]}$ 。空间距离和环境异质性被认为是形成遗传变异和种群多样性的主要因素, 
然而在高原原生湿地土壤中, 它们的相对重要性仍未得到充分认识。鉴于此,该研究以若尔盖高原泥炭沼泽 湿地土壤细菌群落为研究对象, 采用 $16 \mathrm{~S} \mathrm{rDNA}$ 基因测序分析技术, 探究高原泥炭沼泽湿地土壤细菌群落的生 物地理分布模式, 同时依据微生物群落在土壤样本中出现的丰度高低划分为稀有种和丰富种, 研究群落内不 同成员对地理分布模式的响应关系, 以及影响群落多样性的环境驱动因素。该项研究工作的开展, 有助于从 微生物生物地理学的角度解释若尔盖高原泥炭沼泽湿地土壤细菌群落结构及多样性的分布规律和响应机制, 为进一步研究若尔盖湿地土壤微生物地球化学循环过程, 揭示微生物多样性对高原湿地生态系统功能的影响 提供科学依据和理论基础。

\section{1 材料与方法}

\section{1 研究地概况}

若尔盖高原泥炭沼泽湿地位于青藏高原东北部, 川甘两省交界处 $\left(33^{\circ} 25^{\prime}-34^{\circ} 00^{\prime} \mathrm{N}, 102^{\circ} 29^{\prime}-102^{\circ} 59^{\prime} \mathrm{E}\right)$, 为黄河源区的重要组成部分, 具有丰富的动植物资源和生物多样性。气候寒冷湿润, 年均温在 $0.6-1.1^{\circ} \mathrm{C}$ 之 间, 根据第二次全国湿地资源调查结果, 研究区的湿地类型为草本沼泽, 主要优势植物为木里苔草 (Carex muliensis)。若尔盖大沼泽原始生境保存较好, 是我国第一大高原沼泽湿地, 也是世界上面积最大、保存最完 好的高原泥炭沼泽, 是青藏高原高寒湿地生态系统的典型代表。作为重要的生态敏感区、高山生物多样性丰 富带,若尔盖高原沼泽泥炭地在全球生态系统保护中具有重要地位, 在全球碳储量、土壤水分涵养等方面发挥 重要作用 ${ }^{[27]}$ 。

\section{2 实验设计与样品采集}

由于若尔盖泥炭沼泽湿地呈斑块状分布,结合保护区湿地生境特征, 于 2018 年 8 月挑选了原始生境保存 较好的一块典型泥炭沼泽湿地作为研究对象, 从局域尺度 (local scale) 开展微生物地理学研究工作。研究区 沼泽水深在 $0.3-0.5 \mathrm{~m}$ 左右, 为原生生境, 在保护区内部不存在放牧干扰。深人原生沼泽湿地内部进行样品 采集, 结合前人采样策略 ${ }^{[28]}$ 及前期研究基础 ${ }^{[29]}$, 拟采用嵌套采样方案(图 1)。分别设计 3 个 $100 \mathrm{~m}^{2}$ 的样方, 第 1 个样方与第 2 个样方之间的间隔为 $100 \mathrm{~m}$, 第 1 个样方和第 3 个样方之间的间隔为 $1000 \mathrm{~m} 。$ 每个 $100 \mathrm{~m}^{2}$ 的 样方内分别嵌套一个 $10 \mathrm{~m}^{2}$ 和 $1 \mathrm{~m}^{2}$ 两种尺度的小样方。在每个 $100 \mathrm{~m}^{2}$ 的样方内, 共取 10 个土壤芯 $(0-10 \mathrm{~cm})$, 3 个样方一共采集 30 个土壤芯 (图 1, 见红色圆点所示)。该采样策略可以对土壤微生物 $\beta$ 多样性的变化和 更替进行有效评估 ${ }^{[28]}$ 。在每个采样点设置 $0.5 \mathrm{~m} \times 0.5 \mathrm{~m}$ 样方, 将样方内部的植物地上部分收割后带回实验室, 清洗干净并放人 $65^{\circ} \mathrm{C}$ 烤箱中烘至恒重, 用四分位电子天平进行称重得到地上生物量。随后利用荷兰 Eijkelkamp 定深泥炭钻采集 $0-10 \mathrm{~cm}$ 湿地表层土壤样品, 使用环刀 $(7.5 \mathrm{~cm}$ 直径, $5 \mathrm{~cm}$ 高) 和自封袋分装。用 镊子将环刀中的根系挑选出来, 用淘洗法对地下根系冲洗干净后, 放人 $65^{\circ} \mathrm{C}$ 烤箱中烘至恒重, 称重得到地下 生物量。采集的土壤样品一部分放人冻存管后在便携式液氮罐中迅速冷冻, 带回实验室后放人 $-80^{\circ} \mathrm{C}$ 冰箱保 存, 用于土壤微生物分析。

\section{3 土壤理化性质的测定}

土壤容重、土壤孔隙度、含水量等指标的测定使用环刀里的土样。泥炭土壤自然储水量以及最大储水量 分别由自然含水率、饱和含水率换算得到。土壤总氮总磷采用浓硫酸消煮法, 之后采用流动分析仪 ( AA3, Bran+LuebbeCrop, 德国) 测定; 土壤硝态氮、土壤铵态氮采用氯化钾浸提法,之后采用流动分析仪测定; 土壤 $\mathrm{pH}$ 采用玻璃电极法( MP5 $11 \mathrm{pH}$ 计) 按土水比 $1: 2.5$ 测定; 土壤活性磷采用碳酸氢钠一钿锑抗比色法; 土壤活 性碳采用高锰酸钾氧化法; 土壤阳离子交换量采用三氯化六氨合钴浸提一分光光度法。同时,使用 TOC 总有 机碳分析仪 (德国元素 Vario) 测定土壤溶解性有机碳; 使用马弗炉仪器测定土壤灰分; 用氢氟酸-高氯酸-硝酸 消解法测定土壤 $\mathrm{K} 、 \mathrm{Ca} 、 \mathrm{Mg} 、 \mathrm{~S} 、 \mathrm{Fe}$ 以及 Mn 6 种元素( 微波消解仪, 全谱直读电感耦合等离子体发射光谱仪 ( ICPE-9820) ); 利用电感耦合等离子体发射光谱法同时测定土壤中可交换态钾、钙、镁。土壤基本理化指标 测定结果见表 1 。 


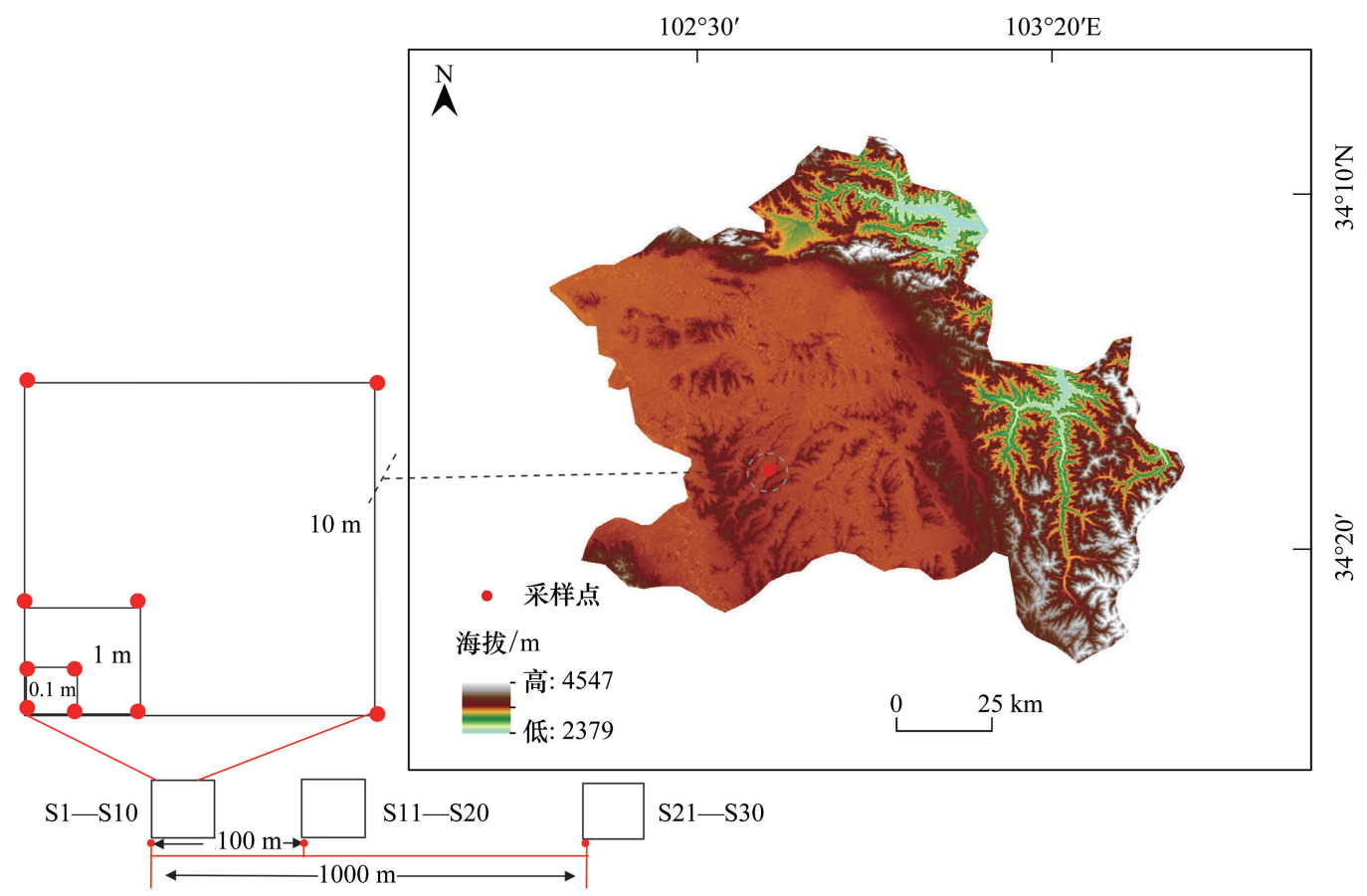

图 1 研究区域位置及采样点示意图

Fig.1 Schematic diagram of the location and sampling points of the study area 图中 $\mathrm{S}$ 为 sample (样品) 的缩写, $\mathrm{S} 1$ 到 $\mathrm{S} 30$ 为 30 个土壤样品的编号

表 1 研究区域土壤理化指标统计表

Table 1 Physical and chemical properties of soil properties in the study area

\begin{tabular}{|c|c|c|c|c|c|c|c|c|c|}
\hline $\begin{array}{l}\text { 指标 } \\
\text { Index }\end{array}$ & $\begin{array}{l}\text { 均值 } \\
\text { Mean }\end{array}$ & $\begin{array}{c}\text { 最小值 } \\
\text { Min }\end{array}$ & $\begin{array}{l}\text { 最大值 } \\
\operatorname{Max}\end{array}$ & $\begin{array}{l}\text { 变异系数 } \\
\text { Coefficient of } \\
\text { variation/\% }\end{array}$ & $\begin{array}{l}\text { 指标 } \\
\text { Index }\end{array}$ & $\begin{array}{l}\text { 均值 } \\
\text { Mean }\end{array}$ & $\begin{array}{c}\text { 最小值 } \\
\text { Min }\end{array}$ & $\begin{array}{l}\text { 最大值 } \\
\operatorname{Max}\end{array}$ & $\begin{array}{l}\text { 变异系数 } \\
\text { Coefficient of } \\
\text { variation/\% }\end{array}$ \\
\hline $\begin{array}{l}\text { 自然储水量 } \\
\text { Natural water storage } /\left(\mathrm{kg} / \mathrm{m}^{2}\right)\end{array}$ & 37.1 & 26.0 & 43.3 & 9.82 & $\begin{array}{l}\text { 总氮 } \\
\text { Total nitrogen/ (mg/g) }\end{array}$ & 16.97 & 10.67 & 32.6 & 21.9 \\
\hline $\begin{array}{l}\text { 饱和储水量 } \\
\text { Saturated water storage } /\left(\mathrm{kg} / \mathrm{m}^{2}\right)\end{array}$ & 41.8 & 36.1 & 46.2 & 4.89 & $\begin{array}{l}\text { 总磷 } \\
\text { Total potassium/( mg/g) }\end{array}$ & 5.64 & 0.34 & 12.8 & 61.7 \\
\hline $\begin{array}{l}\text { 容重 } \\
\text { Bulk density } /\left(\mathrm{g} / \mathrm{cm}^{3}\right)\end{array}$ & 0.15 & 0.11 & 0.22 & 21.23 & $\begin{array}{l}\text { 活性碳 } \\
\text { Labile carbon/ (mg/g) }\end{array}$ & 63.7 & 39.8 & 74.9 & 12.6 \\
\hline $\begin{array}{l}\text { 土壤孔隙度 } \\
\text { Soil porosity/(\%) }\end{array}$ & 0.09 & 0.03 & 0.22 & 52.6 & $\begin{array}{l}\text { 灰分 } \\
\operatorname{Ash} /(\%)\end{array}$ & 25.5 & 4.62 & 46.1 & 37.1 \\
\hline $\begin{array}{l}\text { 地下生物量 } \\
\text { Below-ground biomass } /\left(\mathrm{kg} / \mathrm{m}^{2}\right)\end{array}$ & 4.72 & 1.98 & 7.66 & 30.55 & $\begin{array}{l}\text { 钾 } \\
\text { Potassium kalium/ }(\mathrm{mg} / \mathrm{g})\end{array}$ & 2.47 & 0.82 & 6.05 & 49.4 \\
\hline $\begin{array}{l}\text { 地上生物量 } \\
\text { Above-ground biomass } /\left(\mathrm{kg} / \mathrm{m}^{2}\right)\end{array}$ & 4.68 & 4.06 & 5.52 & 9.62 & $\begin{array}{l}\text { 钻 } \\
\text { Calcium/(mg/g) }\end{array}$ & 9.05 & 3.05 & 24.7 & 50.1 \\
\hline $\mathrm{pH}$ & 6.25 & 5.37 & 7.7 & 7.99 & $\begin{array}{l}\text { 镁 } \\
\text { Magnesium/ (mg/g) }\end{array}$ & 13.5 & 6.04 & 33.5 & 56.15 \\
\hline $\begin{array}{l}\text { 溶解性有机碳 } \\
\text { Dissolved organic carbon/ } \\
(\mathrm{mg} / \mathrm{g})\end{array}$ & 0.82 & 0.01 & 3.39 & 96.0 & $\begin{array}{l}\text { 硫 } \\
\text { Sulfur/ }(\mathrm{mg} / \mathrm{g})\end{array}$ & 1.69 & 0.91 & 2.96 & 29.9 \\
\hline $\begin{array}{l}\text { 有机碳 } \\
\text { Organic carbon/ }(\mathrm{g} / \mathrm{kg})\end{array}$ & 305 & 204 & 393 & 15.7 & $\begin{array}{l}\text { 铁 } \\
\text { Ferrum/ }(\mathrm{mg} / \mathrm{g})\end{array}$ & 163 & 79.6 & 313 & 33 \\
\hline $\begin{array}{l}\text { 阳离子交换量 } \\
\text { Cation exchange capacity/ } \\
(\mathrm{cmol} / \mathrm{kg})\end{array}$ & 40.1 & 21.7 & 61.7 & 33.9 & $\begin{array}{l}\text { 锰 } \\
\text { Manganese/ }(\mathrm{mg} / \mathrm{g})\end{array}$ & 4.74 & 1.21 & 17.4 & 73.9 \\
\hline
\end{tabular}




\begin{tabular}{|c|c|c|c|c|c|c|c|c|c|}
\hline $\begin{array}{l}\text { 指标 } \\
\text { Index }\end{array}$ & $\begin{array}{l}\text { 均值 } \\
\text { Mean }\end{array}$ & $\begin{array}{l}\text { 最小值 } \\
\text { Min }\end{array}$ & $\begin{array}{l}\text { 最大值 } \\
\text { Max }\end{array}$ & $\begin{array}{l}\text { 变异系数 } \\
\text { Coefficient of } \\
\text { variation } / \%\end{array}$ & $\begin{array}{l}\text { 指标 } \\
\text { Index }\end{array}$ & $\begin{array}{l}\text { 均值 } \\
\text { Mean }\end{array}$ & $\begin{array}{l}\text { 最小值 } \\
\text { Min }\end{array}$ & $\begin{array}{l}\text { 最大值 } \\
\operatorname{Max}\end{array}$ & $\begin{array}{l}\text { 变异系数 } \\
\text { Coefficient of } \\
\text { variation/\% }\end{array}$ \\
\hline $\begin{array}{l}\text { 有效磷 } \\
\text { Available phosphorus } /(\mathrm{mg} / \mathrm{kg})\end{array}$ & 14.6 & 3.62 & 33.0 & 53.6 & $\begin{array}{l}\text { 交换态钾 } \\
\text { Exchangeable potassium/(mg/g) }\end{array}$ & 0.12 & 0.04 & 0.24 & 48.8 \\
\hline $\begin{array}{l}\text { 硝态氮 } \\
\text { Nitrate nitrogen } /(\mathrm{mg} / \mathrm{kg})\end{array}$ & 60.8 & 24 & 308 & 85.82 & $\begin{array}{l}\text { 交换态钙 } \\
\text { Exchangeable calcium/(mg/g) }\end{array}$ & 7.8 & 1.63 & 14.4 & 37.2 \\
\hline $\begin{array}{l}\text { 铵态氮 } \\
\text { Ammonium nitrogen/(mg/kg) }\end{array}$ & 23.32 & 4.59 & 70.2 & 77.73 & $\begin{array}{l}\text { 交换态镁 } \\
\text { Exchangeable magnesium/ } \\
(\mathrm{mg} / \mathrm{g})\end{array}$ & 2.13 & 0.8 & 6.74 & 60.0 \\
\hline
\end{tabular}

1.4 土壤 DNA 提取和 $16 \mathrm{~S} \mathrm{rDNA}$ 扩增子测序

土壤微生物 DNA 提取使用 Ezup 柱式土壤基因组 DNA 抽提试剂盒, 按试剂盒操作说明书提取,并采用 0 . $8 \%$ 琼脂糖凝胶电泳检测 DNA。16S 保守序列片段的扩增引物使用 515F ( $5^{\prime}$ - GTGCCAGCMGCCGCGGTAA$\left.3^{\prime}\right)$ 和 $806 \mathrm{R}\left(5^{\prime}-\text { GGACTACHVGGGTWTCTAAT- } 3^{\prime}\right)^{[30]}$ 。以 10 倍稀释后的基因组 DNA 为模板, 根据测序区 域的选择, 使用带 Barcode 的特异性引物进行 PCR 扩增, 每个样本进行三个 PCR 技术重复。PCR 产物与 1/6 体积的 6X loading buffer 混合, 使用 2\%琼脂糖凝胶进行电泳检测。对目的条带进行割胶回收, 使用 QIAquick Gel Extraction Kit( QIAGEN) 试剂盒, 回收后的 PCR 纯化产物使用 Qubit@ 2.0 Fluorometer( Thermo Scientific)进 行定量, 最后等摩尔量混合。建库使用 TruSeq DNA PCR一Free Sample Prep Kit 试剂盒, 构建好的文库经过定 量和文库检测合格后, 使用罗宁生物的 Hiseq 2500 平台 PE250 模式测序。

\section{5 采样点的地理距离获取}

每个采样点的空间地理坐标由手持 GPS (eTrex enture, Garmin, Olathe, KS, USA) 进行记录,之后采用平 面直角坐标系来计算每个采样点的相对距离 ( 以第一个采样点为原点, 图 1)。使用 R 语言中的 Vegan 包计算 采样点之间的两两地理距离, 从而创建采样点之间的地理距离矩阵。

\section{6 数据分析与处理}

\subsection{1 群落组成及 Alpha 多样性分析}

使用 R 语言中的 Vegan 包进行数据预处理与 alpha 多样性和相对丰度的计算, 将在所有样品中出现且丰 度大于 2 的 OTU 定义为核心微生物 (core microbiome), 使用 grid 包和 ggplot2 包将数据进行可视化处理。

\subsection{2 土壤微生物群落相似性与地理距离的相关性分析}

通过将全部 OTU 分类单元重新划分为稀有种 (Endemic taxa) (在所有样品中出现的频率低于 $25 \%$ 的 OTU) 和丰富种 (Ubiquitous taxa) (在所有样品中出现的频率高于 $75 \%$ 的 OTU), 分别产生 4057 个和 716 个 OTU 分类单元。随后, 通过非度量多维标度 (Bray-Curtis) 距离 ${ }^{[31]}$, 采用非参数多变量统计检验和相似性分 析 (999 个排列), 测定细菌总群落、稀有种群落、丰富种群落在局域空间尺度上不同样本之间的群落结构相似 性 ${ }^{[32]}$ 。细菌群落的周转速率用衰减率表示, 该指标为地理距离 ( $\ln$ 对数转换) 与群落相似性 ( $\ln$ 对数转换) 关 系的普通最小二乘回归(Ordinary Least Squares Regression)的斜率。斜率的计算公式如下:

$$
\ln (S)=\ln (a)+z \ln (G)
$$

式中, $S$ 为微生物群落相似性, $G$ 为地理距离, $a$ 为截距参数, $z$ 为衰减曲线的斜率, 反映细菌群落的周转 速率 ${ }^{[33]}$ 。

\subsubsection{Mantel 检验、方差分解分析}

为了分析环境变量以及地理距离对微生物群落组成的影响, 使用 R 语言中的 ggcor 包进行 Mantel 检验分 析, 检验不同群落组成和环境变量之间的 Spearman 相关性。同时,使用 vegan 包进行基于距离的攵余分析 (Distance-based redundancy analysis, db-RDA)。

邻体矩阵主坐标 (principal coordinates of neighbor matrices, PCNM) 分析能够获得样本间空间关系的分解 
向量,显著的 PCNM 变量能直接解释空间尺度对物种的贡献 ${ }^{[34]}$ 。PCNM 分析通过对研究尺度范围内的空间 距离建立截尾矩阵,通过主轴分析法进行处理,得到 PCNM1 …P PCNMn,PCNM1 表示整个研究尺度内的空间 信息,属大尺度;PCNM2、…PCNMn 代表的尺度信息依次减少。得到空间因子数据后,结合土壤理化数据,采 用方差分解分析 (Variance Partitioning Analysis, VPA) 来评估空间因子、土壤因子对细菌总群落、稀有种群落、 丰富种群落多样性组成和结构变化的相对贡献。PCNM 分析以及 VPA 分析均使用 R 语言中的 vegan 包 进行。

\section{2 结果与分析}

\section{1 土壤细菌群落丰度及多样性分析}

\subsection{1 群落组成}

在所有的土壤样本中,一共获得 986532 条高质量的细菌序列, 在 $97 \%$ 的相似水平下进行 OTU 聚类分析 后,共得到 6456 个分类单元。通过将全部 OTU 分类单元重新划分为稀有种和丰富种,分别产生 4057 和 716 个 OTU。我们比较了稀有种、丰富种和总细菌群落在门水平和属水平上相对丰度在前 10 的物种组成特征 (图 2)。

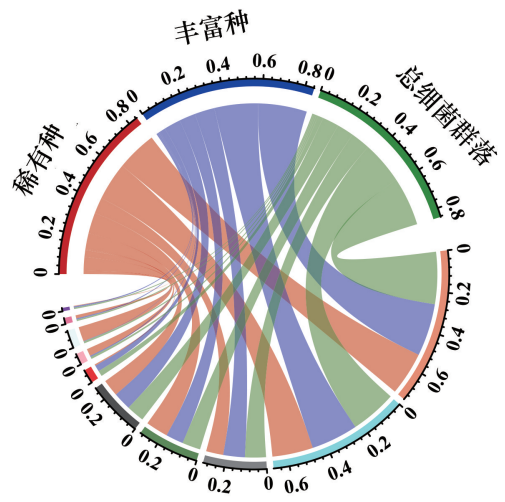

门水平

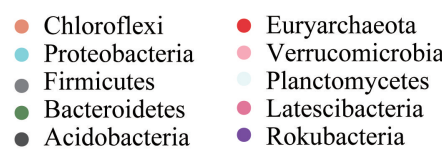

- Chloroflexi

- Firmicutes

- Acidobacteria

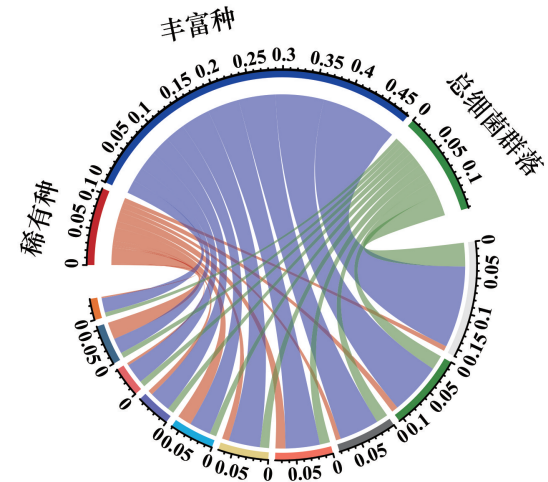

属水平

$$
\begin{array}{ll}
\text { Lactobacillus } & \text { Bacteroides } \\
\text { - Thauera } & \text { Anaerolineaceae UCG } 001 \\
\text { - Methanobacterium } & \text { Ornatilinea } \\
\text { - Geobacter } & - \text { Ruminococcaceae UCG } 014 \\
\text { Anaerolinea } & - \text { Bacillus }
\end{array}
$$

图 2 稀有种、丰富种和总细菌群落在门水平和属水平上的相对丰度 (前 10) 图

Fig.2 Relative abundance (top 10) of endemic, ubiquitous and total bacterial communities at phylum and genus levels 图例中文注释,绿弯菌门:Chloroflexi; 变形菌门:Proteobacteria; 厚壁菌门:Firmicutes; 拟杆菌门: Bacteroidetes; 酸杆菌门: Acidobacteria; 广古菌 门:Euryarchaeota; 疮微菌门: Verrucomicrobia; 浮霉菌门: Planctomycetes; Latescibacteria 菌门: Latescibacteria; Rokubacteria 菌门: Rokubacteria; 乳 杆菌属: Lactobacillus; 陶厄氏菌属: Thauera; 甲烷杆菌属: Geobacter; 地杆菌属: Methanobacterium; 厌氧绳菌属: Anaerolinea; 拟杆菌属: Bacteroides; 厌氧菌科 UCG.001: Anaerolineaceae UCG.001; Ornatilinea 属: Ornatilinea; 球菌科 UCG. 014: Ruminococcaceae UCG. 014; 芽孢杆菌 属: Bacillus

经微生物 $16 \mathrm{~S}$ rDNA 基因测序,共检测到 54 个菌门和 934 个菌属。其中, 19 个菌门和 121 个菌属的平均 丰度高于 $1 \%$ 。绿弯菌门 (Chloroflexi) 是显著的优势菌门,在稀有种群、丰富种群和总细菌群落中其所占丰度 分别达 $21.88 \% 、 26.45 \%$ 和 $26.25 \%$, 其他优势菌落分别为变形菌门 (Proteobacteria)、厚壁菌门(Firmicutes)、拟 杆菌门(Bacteroidetes)、酸杆菌门( Acidobacteria)、广古菌门(Euryarchaeota)、疮微菌门( Verrucomicrobia)、浮霉 菌门(Planctomycetes)、Latescibacteria 和 Rokubacteria。在属水平上, 乳杆菌属 (Lactobacillus) 是明显的优势菌 属,在稀有种群、丰富种群和总细菌群落中其所占丰度分别达 $0.7 \% 、 11 \%$ 和 $3 \%$ 。在稀有种中, Ruminococcaceae UCG-014 是优势菌属。 
此外,通过 30 个土壤微生物样本信息,构建了基于泥炭土壤微生物的核心微生物群 ( core microbiome), 共计 278 个 OTU 分类单元,分属于 17 个门水平和 84 个属水平。图 3 列举了核心微生物在门水平和属水平划 分上相对丰度前 10 的核心微生物。其中,在门水平上丰度前三的细菌分别是绿弯菌门(Chloroflexi)、变形菌 门(Proteobacteria) 和厚壁菌门(Firmicutes), 这些微生物在核心微生物群中所占丰度高达 $69 \%$; 在属水平上, 丰度排前三的微生物分别是拟杆菌属 (Bacteroides)、球菌科 UCG.014 (Ruminococcaceae UCG-014) 和甲烷杆菌 属 (Methanobacterium) , 其所占丰度为 $18.04 \%$ 。

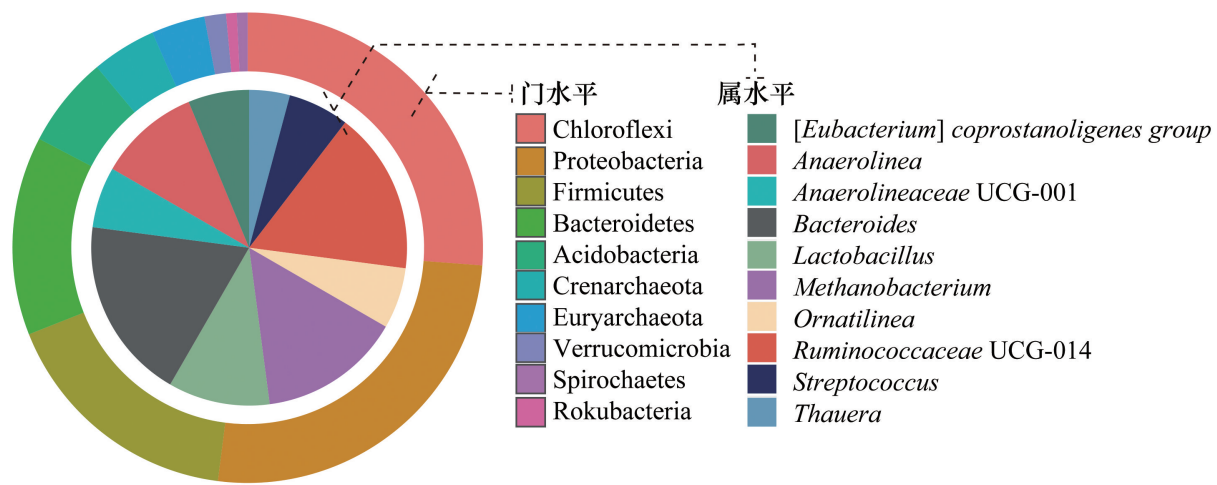

图 3 基于 30 个土壤样本构建的门水平和属水平上相对丰度前 10 的核心微生物

Fig.3 Relative abundance of top 10 core microorganisms at the phylum level and genus level

图例中文注释, 泉古菌门: Crenarchaeota; 螺旋体门: Spirochaetes; [ Eubacterium ] coprostanoligenes group 属: [ Eubacterium ] coprostanoligenes group; 乳杆菌属: Lactobacillus; 链球菌属: Streptococcus

\subsubsection{Alpha 多样性}

对研究区域所有采样点土壤细菌群落的 Alpha 多样性指数分析显示 (图 4), Chao1 指数、Shannon 指数和 Simpson 指数分别介于 1663-3571、3.21-6.49 和 0.98-0.99 之间,若尔盖高原湿地土壤样品具有较高的微生 物多样性。同时发现, Chao 1 指数的变异系数 $(14.71 \%)$ 大于 Shannon 指数 $(3.21 \%)$ 和 Simpson 指数 $(0.32 \%)$ 。

2.2 细菌群落相似性的距离衰减特征分析

为探索高原泥炭原生沼泽湿地土壤中的微生物群落是否存在生物地理分布模式, 对微生物群落相似性和 地理距离之间的关系进行分析, 并获得群落相似性随地理距离变化的衰减率特征。结果表明, 稀有种、丰富种 和总细菌群落的相似性均随着地理距离的增加而衰减 (图 5), 表明高原泥炭湿地土壤微生物的空间分布特征 符合生物地理分布的一般模式。通过比较, 发现细菌群落的周转速率 (图 5 , 斜率 Slope) 在不同群落中存在差 异。总体上, 总细菌群落的距离衰减斜率 ( Slope $\left.=-0.026 ; P<0.001 ; R^{2}=0.139\right)$ 高于稀有种 ( Slope $=-0.006 ; P$ $\left.=0.004 ; R^{2}=0.056\right)$ 和丰富种 (Slope $\left.=-0.025 ; P<0.001 ; R^{2}=0.112\right) 。 3$ 个细菌群落对空间尺度的依赖性由大 到小分别是总细菌群落、丰富种和稀有种。由此我们可以得出, 在原始生境保存较好的若尔盖泥炭沼泽高原 湿地生境中,土壤微生物群落的相似性随地理距离的增加而衰减,稀有种的周转速率则低于丰富种。

\section{3 稀有种、丰富种和总细菌群落对环境因子的响应}

对 3 种细菌群落和环境因子进行 Mantel 检验分析。结果显示(图 6), 地上生物量与 3 种微生物群落之间 表现出极显著相关性 $(0.001<P<0.01)$, 是导致微生物群落在地理空间上差异分布的主要环境因子。同时, 稀 有种群落还与土壤的硫含量存在极显著相关性 $(0.001<P<0.01)$, 与土壤 $\mathrm{pH}$ 、活性磷和 $\mathrm{Mn}$ 之间存在显著关系 $(0.01<P<0.05)$ 。

为了进一步明确驱动微生物群落多样性在局域尺度上造成差异的关键环境因子, 基于 Bray一Curtis 距离 的约束主坐标分析表明 (图 7), 稀有种、丰富种和总细菌群落多样性变异的 $11.54 \%$ 、38.20\%和 31.85\%可以用 前两个主成分 (CAP1 和 CAP2) 来解释。按环境因子对 3 种细菌群落组成差异性影响的递减顺序(前向选 

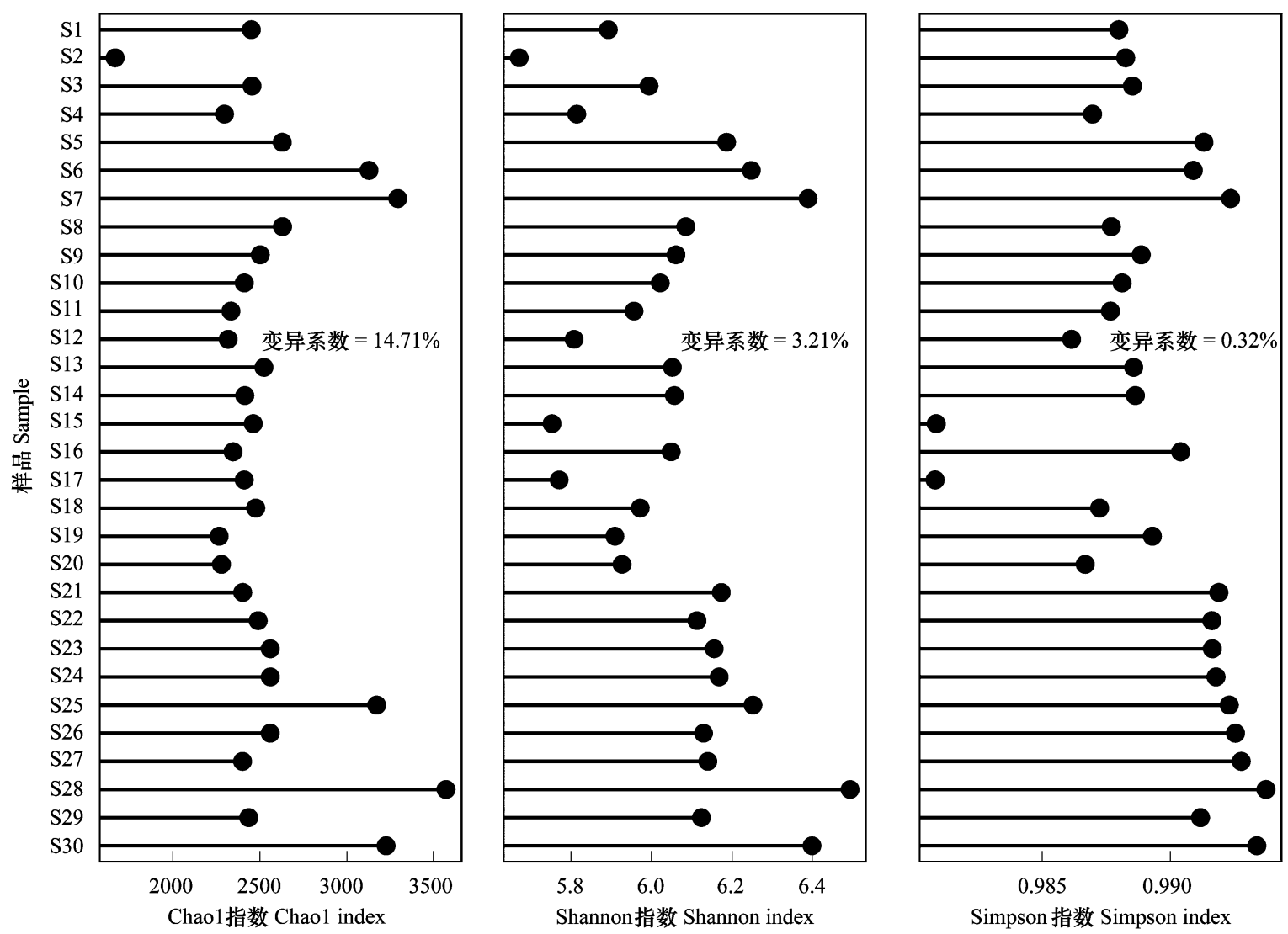

图 4 细菌群落 Alpha 多样性指数变化 Cleveland 点图

Fig.4 Cleveland point diagram of changes in the Alpha diversity index of bacterial community

$\mathrm{S} 1$ 到 S30 为 30 个土壤样品的编号

稀有种

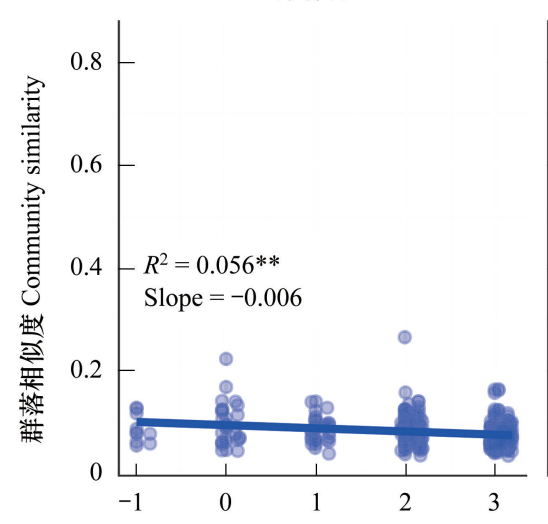

丰富种

总细菌群落

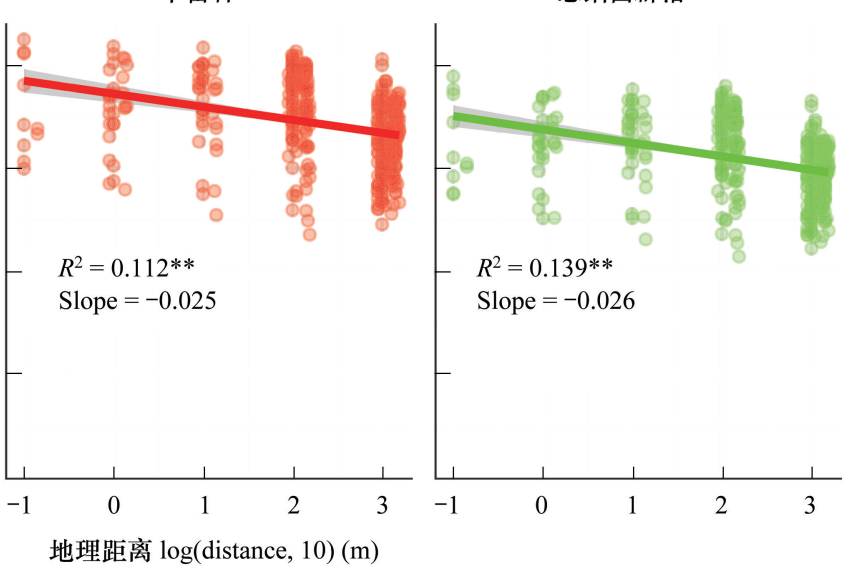

图 5 群落相似性的地理距离衰减图

Fig.5 Geographical distance decay diagram of community similarity

择), 这些显著因子分别为地上生物量、活性磷 (丰富种、总细菌群落) 和硫含量 (稀有种), 地上生物量是影响 3 种细菌群落组成多样性的关键环境因子; 在稀有种群落中, CAP1 与地上生物量呈显著负相关 $\left(R^{2}=0.37, P<\right.$ $0.001)$, 而在丰富种群落 $\left(R^{2}=0.38, P<0.001\right)$ 和总细菌群落 $\left(R^{2}=0.43, P<0.001\right)$ 中则为显著正相关。该分析 
结果进一步验证了 Mantel 分析检验结果。

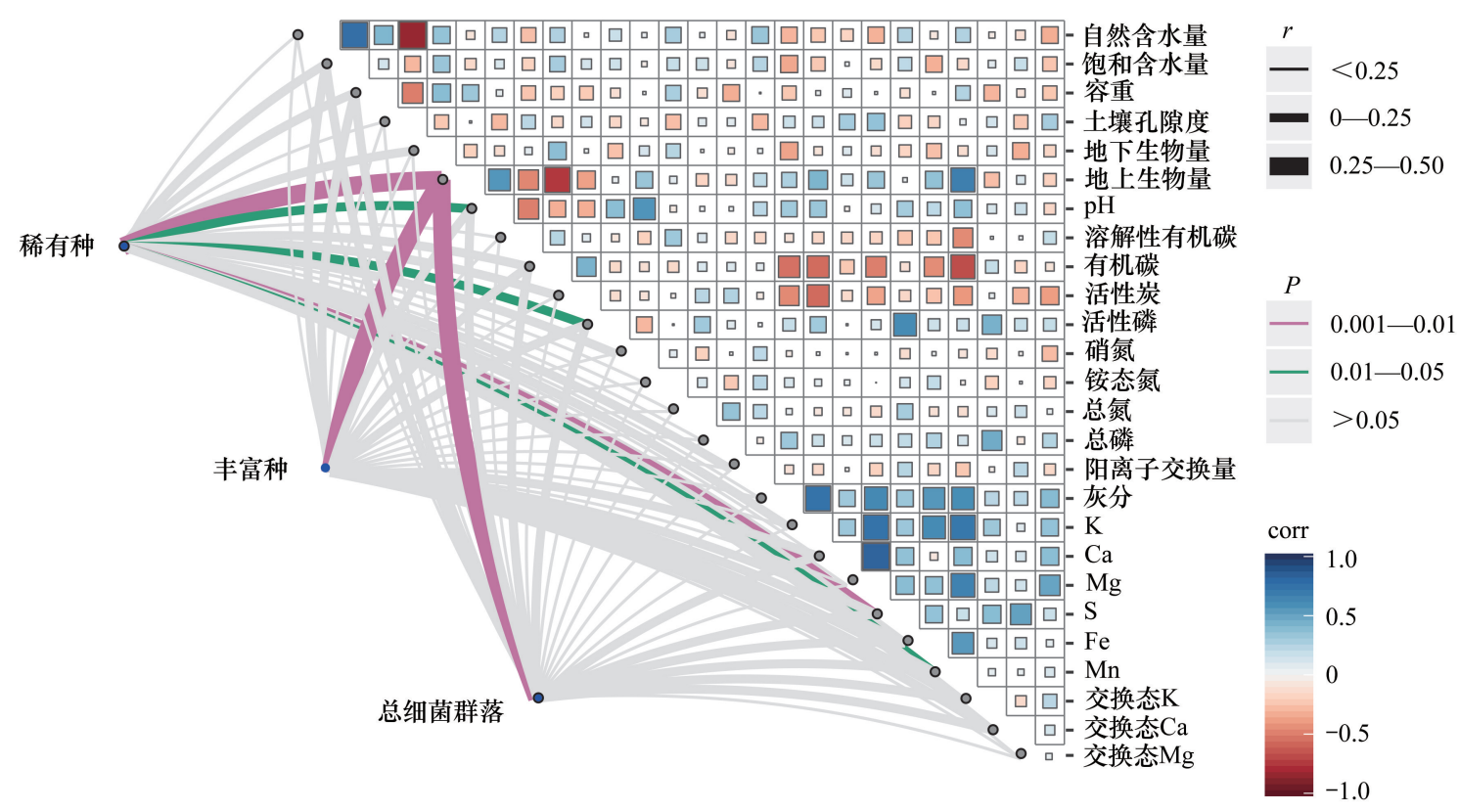

图 6 环境因子和 3 类细菌群落的 Mantel 检验

Fig.6 Mantel test of environmental factors and 3 bacterial communities

右半图为环境因子的两两比较, 用颜色梯度表示 Spearman 相关系数大小; 左半图为 3 种微生物群落与环境因子之间的关系, 连接线条的宽 度对应 Mantel's r 统计量,线条颜色表示基于 9999 个排列的统计显著性
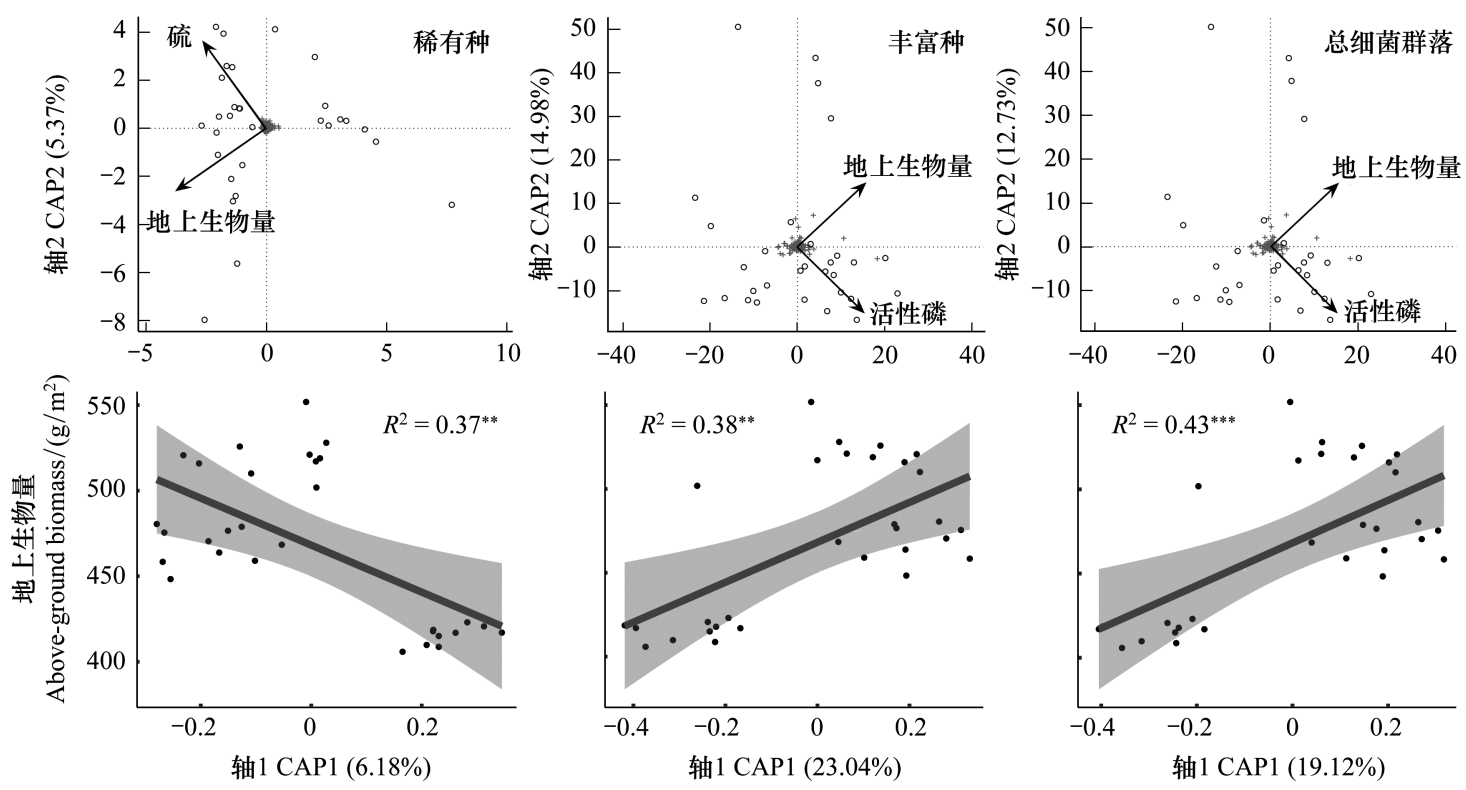

图 73 种细菌群落和环境变量的圥余分析 $(\mathrm{db}-\mathrm{RDA})$

Fig.7 Redundancy analysis of three bacterial communities and environmental variables (db-RDA)

下半部分图是地上生物量与其样本在 CAP 第一轴上的得分做的回归分析; CAP : 基于 Bray-curtis 距离的主坐标约束分析 Constrained analysis of principal coordinates based on bray-curtis distance

2.4 环境因子与空间因子对微生物群落构建的相对贡献

采用 VPA 方法分析环境因子(土壤环境因子) 和空间因子(PCNM) 对稀有种群、丰富种群和整体细菌群 
落组装的相对贡献。图 8 显示在 3 个细菌群落中, 环境因子和空间因子对群落结构贡献的总解释量分别为 $4.93 \% 、 27.84 \%$ 和 $26.63 \%$, 其中, 空间因子在 3 种细菌群落的单独解释量分别为 $1.39 \% 、 3.59 \%$ 和 $3.85 \%$; 环境 因子在 3 个群落中的单独解释量分别为 $1.57 \% 、 7.27 \%$ 和 $6.98 \%$; 空间因子、环境因子在 3 个细菌群落中的共 同解释量分别为 $1.96 \% 、 16.98 \%$ 和 $15.80 \%$ 。总体上,在局域尺度上,环境因子对 3 种细菌群落组成差异性的 贡献度要高于空间因子; 稀有种群的 VPA 分析结果解释度明显低于整体细菌群落和丰富种群, 可能是因为稀 有种群落的产生具有较大的随机性, 主要由随机作用(非决定作用) 调控其群落构建 (图 5)。
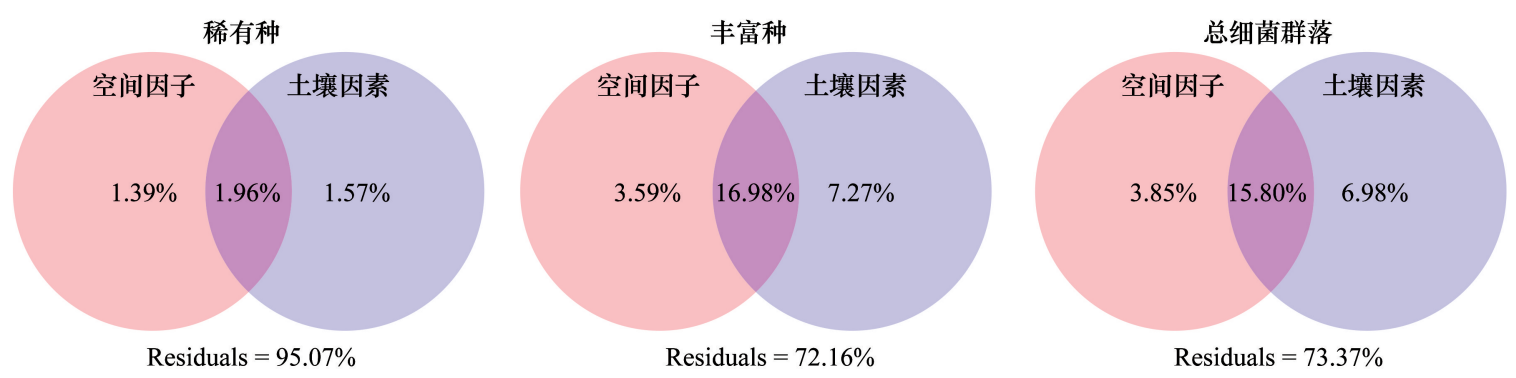

图 8 空间因子、土壤因素对细菌群落结构相对贡献的方差分解分析

Fig.8 Variation partitioning analysis of the relative contributions of spatial factors and soil factors to bacterial community structure

通过对解释变量做前向选择分析 (表 2), 发现空间因子 PCNM1、PCNM2 为主要解释变量 $(P<0.05)$, 说明 覆盖整个采样点的空间特征对样点之间微生物群落结构的差异具有显著影响; 地上生物量和活性磷为丰富种 和总细菌群落的主要解释因子, 而在稀有种群中则为土壤硫含量和地上生物量。

表 2 方差分解分析 (VPA) 结果统计表

Table 2 Statistical table of variance partitioning analysis (VPA) results

\begin{tabular}{|c|c|c|c|c|c|c|c|c|c|}
\hline $\begin{array}{l}\text { 细菌类群 } \\
\text { Bacterial } \\
\text { community }\end{array}$ & $\begin{array}{l}\text { 预测因子 } \\
\text { Predictor }\end{array}$ & $\begin{array}{l}\text { 变量 } \\
\text { Variable }\end{array}$ & $R^{2}$ & $R^{2} \mathrm{Cum}$ & Adj $R^{2} \mathrm{Cum}$ & $F$ & $\begin{array}{c}\text { 显著性 } \\
\text { Pval }\end{array}$ & $\begin{array}{c}\text { 单独解释 } \\
\text { Unique }\end{array}$ & $\begin{array}{c}\text { 共同解释 } \\
\text { Shared }\end{array}$ \\
\hline 稀有种 & 空间因子 & PCNM1 & 0.054 & 0.054 & 0.021 & 1.608 & 0.001 & 0.014 & 0.020 \\
\hline \multirow[t]{3}{*}{ Endemic taxa } & & PCNM2 & 0.046 & 0.100 & 0.034 & 1.377 & 0.003 & & \\
\hline & 土壤因素 & 硫 & 0.051 & 0.051 & 0.017 & 1.511 & 0.001 & 0.016 & \\
\hline & & 地上生物量 & 0.051 & 0.102 & 0.035 & 1.524 & 0.001 & & \\
\hline 丰富种 & 空间因子 & PCNM1 & 0.162 & 0.162 & 0.132 & 5.414 & 0.003 & 0.036 & 0.170 \\
\hline \multirow[t]{3}{*}{ Ubiquitous taxa } & & PCNM2 & 0.098 & 0.260 & 0.206 & 3.596 & 0.014 & & \\
\hline & 土壤因素 & 地上生物量 & 0.162 & 0.162 & 0.133 & 5.429 & 0.002 & 0.073 & \\
\hline & & 活性磷 & 0.132 & 0.295 & 0.242 & 5.065 & 0.001 & & \\
\hline 总细菌群落 & 空间因子 & PCNM1 & 0.159 & 0.159 & 0.129 & 5.291 & 0.001 & 0.039 & 0.158 \\
\hline \multirow{3}{*}{$\begin{array}{l}\text { Total bacterial } \\
\text { community }\end{array}$} & & PCNM2 & 0.093 & 0.252 & 0.196 & 3.356 & 0.009 & & \\
\hline & 土壤因素 & 地上生物量 & 0.152 & 0.152 & 0.122 & 5.014 & 0.001 & 0.070 & \\
\hline & & 活性磷 & 0.129 & 0.281 & 0.228 & 4.851 & 0.001 & & \\
\hline
\end{tabular}

PCNM : 邻体矩阵主坐标分析, Principal Coordinates of Neighbor Matrices

\section{3 讨论}

\section{1 若尔盖高原湿地土壤微生物群落结构特征}

前人针对若尔盖高原湿地土壤微生物开展了大量研究工作。如 Zhong 等 ${ }^{[24]}$ 发现地下水位下降降低了原 核生物群落的 alpha 多样性,微生物群落的垂向分布特征主要受地下水位波动影响。Tang 等 ${ }^{[6]}$ 研究表明在若 尔盖地区, 土壤类型对细菌群落的影响大于土壤深度对细菌群落的影响。 $\mathrm{Gu}$ 等 ${ }^{[26]}$ 发现土壤退化导致若尔盖 细菌和古菌群落的网络关联模式发生变化。Yang 等 ${ }^{[25]}$ 研究发现泥炭地退化减少了表层和深层土壤中的产 
甲烷菌的数量, 甲烷排放下降。Cui 等 ${ }^{[22]}$ 研究表明温度增加了高寒湿地甲烷排放, 而植被对甲烷菌群落组成 有显著贡献,并与甲烷排放密切相关。目前,在若尔盖开展的研究工作主要集中在生境变化及扰动对微生物 的影响,这些研究工作为我们进一步揭示若尔盖土壤微生物的地理分布格局打下了基础。

通过对比发现,不同区域的泥炭土壤细菌群落组成具有相似性。研究者 ${ }^{[13]}$ 在对我国东北泥炭土壤细菌 群落的研究中发现,酸杆菌门(Acidobacteria)、放线菌门(Actinobacteria)、变形菌门( Proteobacteria)、拟杆菌门 (Bacteroidetes)、绿弯菌门(Chloroflexi) 等为土壤中的优势细菌群落。而在本研究中, 若尔盖泥炭土壤的优势 细菌群落为绿弯菌门 (Chloroflexi)、变形菌门 (Proteobacteria)、厚壁菌门 (Firmicutes)、拟杆菌门 (Bacteroidetes)、酸杆菌门(Acidobacteria) 等组成, 在群落组成结构上与其他区域的泥炭土壤微生物组成具有 相似性。基于前人的研究结果, 我们认为若尔盖高原泥炭沼泽湿地中的这些土壤细菌群落是驱动若尔盖泥炭 土壤生物地球化学循环的主要参与者, 并同时参与了该区域湿地生境的形成与演化。然而, 有关细菌群落在 高原湿地生境中所发挥的具体功能仍需要进一步探索和研究。

3.2 若尔盖高原湿地土壤微生物地理模式

虽然已有大量研究报道了不同生境中土壤微生物的生物地理模式,但少有研究关注人类活动干扰较少的 高原湿地生境中的微生物生物地理模式,也少有研究阐明了微生物群落中不同类群群落相似度随地理距离的 变化情况 ${ }^{[10-13]}$ 。在本研究中,稀有种、丰富种和总细菌群落的相似度随地理距离的增加而衰减,证实了在高 原泥炭沼泽湿地中土壤微生物也存在生物地理分布模式; 3 种细菌群落的距离衰减斜率在局域尺度上存在差 异, 且稀有种群落的相似度距离衰减斜率低于丰富种群, 这与其他研究者在水稻土壤细菌群落中的发现有所 不同 ${ }^{[18]}$ 。在本研究中, 稀有种群在 30 个土壤样品中的群落相似度低于 $20 \%$, 丰富种群的相似度则高于 $70 \%$ (图 5)。稀有种在不同样品之间的差异主要由群落的演替、变更导致, 而丰富种在不同样品之间的差异主要 由群落的丰度高低导致。结合他们各自的距离衰减斜率规律 (稀有种群落的相似度距离衰减斜率低于丰富 种群), 我们认为若尔盖高原泥炭土壤微生物相似性的地理衰减主要由高丰度的优势群落调控,物种丰度的 变化是导致微生物群落地理距离衰减的主要因素。

\section{3 环境因子对土壤微生物群落的影响}

环境因子是影响微生物群落结构的重要因素 ${ }^{[11,17]}$ 。在本研究中, 通过 Mantel 检验和圥余分析得出, 地上 生物量与 3 种微生物群落之间表现出极显著相关性 $(0.001<P<0.01 ; 0.25<R<0.5)$; 前人对东北黑土地细菌群 落的研究发现, 土壤细菌群落的组成和多样性主要受土壤 $\mathrm{pH}$ 值和土壤总碳含量的影响 ${ }^{[13]}$; 在长白山土壤细 菌群落的研究中也发现土壤 $\mathrm{pH}$ 值决定了长白山细菌群落的空间分布 ${ }^{[16]}$ 。在本研究中, 土壤 $\mathrm{pH}$ 对稀有种群 落多样性影响显著, 但对丰富种和总细菌群落的影响并不明显, 因此我们认为该因素可能是调控若尔盖湿地 土壤微生物演替过程的主要因素, 而对微生物丰度变化的影响较弱。地上生物量对细菌群落多样性的显著影 响这一研究结果具有重要的指示作用, 即土壤浅层的细菌群落可能与地上部分的植物多样性和生物量之间存 在互作。总体上, 本研究中发现对土壤微生物群落组成结构起重要影响的环境因子与前人在其他地区的研究 结果大致相同,即植物生产力、土壤 $\mathrm{pH}$ 等因素始终是全球土壤微生物最重要的预测因子 ${ }^{[35]}$ 。

3.4 环境因子和空间距离对土壤微生物群落构建的相对贡献

Jennifer 等 ${ }^{[33]}$ 通过比较盐沼沉积物中氨氧化细菌群落的组成, 发现地理距离对局部尺度的微生物群落结 构相似性影响显著, 并认为距离效应的产生与生态漂移有关。然而, 随着地理距离增加, 微生物群落的地理衰 减模式发生变化。Gao 等 ${ }^{[18]}$ 研究了水稻土细菌群落组装的空间尺度依赖性, 发现稀有种群、丰富种群和总细 菌群落在局域尺度 $(1-113 \mathrm{~m})$ 、中观尺度 $(3.4-39 \mathrm{~km})$ 和区域尺度 $(103-668 \mathrm{~km})$ 内的空间依赖性存在差异。

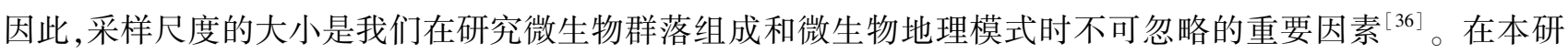
究中, 我们在局域尺度上对不同细菌群落的空间尺度依赖性进行了研究,发现不同细菌群落的空间依赖性存 在差异, 从而进一步论证了前人的研究结果。此外,有研究者运用 VPA 分析揭示中国东部沿海地区水稻土壤 和玉米土壤中影响古生菌群落构建的空间因素和环境因素, 定量分析空间因子、土壤因子和气候因素对微生 
物群落构建的相对贡献 ${ }^{[14]}$ 。研究发现, 影响玉米和水稻土古生菌群落构建的相对贡献由大到小依次为土壤 理化因子、空间因子和气候因子, 该结果与本研究中得到的结果具有相似性(图 8、表 2), 表明在我们所调查 的局域尺度上, 若尔盖泥炭湿地土壤微生物群落对环境异质性的响应较为强烈, 是群落微生物构建的主要影 响因素。

\section{4 结论}

1) 若尔盖高原泥炭沼泽湿地中土壤细菌多样性较高,共包括 54 个菌门和 934 个菌属。其中, 19 个菌门 和 121 个菌属的平均丰度高于 $1 \%$ 。在门水平上,绿弯菌门(Chloroflexi) 、变形菌门(Proteobacteria) 和拟杆菌 门(Bacteroidetes) 构成泥炭土壤核心微生物; 在属水平上则为拟杆菌属 (Bacteroides)、球菌科 UCG. 014 (Ruminococcaceae UCG-014) 和甲烷杆菌属 (Methanobacterium)。

2) 若尔盖高原泥炭沼泽湿地土壤细菌群落在局域尺度上存在较为明显的生物地理分布模式, 即细菌群 落相似性随地理距离的增加而衰减。在 3 种细菌群落中,群落的周转速率由大到小分别为总细菌群落、丰富 种和稀有种。

3) 地上生物量是影响高原泥炭沼泽湿地土壤细菌群落空间分布特征的关键环境因子; 影响稀有种群落 空间特征的环境因子还包括土壤硫含量、活性磷、 $\mathrm{Mn}$ 和土壤 $\mathrm{pH}$ 值。在局域尺度上,土壤理化因子对高原泥 炭沼泽湿地土壤细菌群落构建的相对贡献大于空间因子。

\section{参考文献 (References) :}

[ 1 ] Evenson G R, Golden H E, Lane C R, McLaughlin D L, D'amico E. Depressional wetlands affect watershed hydrological, biogeochemical, and ecological functions. Ecological Applications, 2018, 28(4) : 953-966.

[ 2 ] Yang T X, Sheng L X, Zhuang J, Lv X G, Cai Y P. Function, restoration, and ecosystem services of riverine wetlands in the temperate zone. Ecological Engineering, 2016, 96: 1-7.

[ 3 ] Liu J, Ye S Y, Yuan H M, Ding X G, Zhao G M, Yang S X, He L, Wang J, Pei S F, Huang X Y. Metal pollution across the upper delta plain wetlands and its adjacent shallow sea wetland, northeast of China: implications for the filtration functions of wetlands. Environmental Science and Pollution Research, 2018, 25(6): 5934-5949.

[ 4 ] Wang H, Teng C Y, Li H Y, Sun X Z, Jiang C L, Lou L P, Yue C L, Zhang Z J. Microbial community shifts trigger loss of orthophosphate in wetland soils subjected to experimental warming. Plant Soil, 2018, 424: 351-365.

[ 5 ] Li H, Chi Z F, Li J L, Wu H T, Yan B X. Bacterial community structure and function in soils from tidal freshwater wetlands in a Chinese delta: potential impacts of salinity and nutrient. Science of the Total Environment, 2019, 696: 134029.

[ 6 ] Tang J, Ding X, Wang L M, Xu Q R, Yang Z R, Zhao J, Sun Q, Feng S, Zhang J. Effects of wetland degradation on bacterial community in the Zoige Wetland of Qinghai-Tibetan Plateau (China). World Journal of Microbiology and Biotechnology, 2012, 28(2) : 649-657.

[ 7 ] Jansson J K, Tas N. The microbial ecology of permafrost. Nature Reviews Microbiology, 2014, 12(6) : 414-425.

[ 8 ] Jansson J K, Hofmockel K S. Soil microbiomes and climate change. Nature Reviews Microbiology, 2020, 18(1) : 35-46.

[ 9 ] Baas-Becking L G M. Geobiologie of Inleiding tot de Milieukunde. The Hague: W P Van Stockum \& Zoon, 1934.

[ 10] Wang X B, Lü X T, Yao J, Wang Z W, Deng Y, Cheng W X, Zhou J Z, Han X G. Habitat-specific patterns and drivers of bacterial $\beta$-diversity in China's drylands. The ISME Journal, 2017, 11(6): 1345-1358.

[11] Jiao S, Xu Y Q, Zhang J, Lu Y H. Environmental filtering drives distinct continental atlases of soil archaea between dryland and wetland agricultural ecosystems. Microbiome, 2019, 7: 15 .

[12] Zeng Q C, An S S, Liu Y, Wang H L, Wang Y. Biogeography and the driving factors affecting forest soil bacteria in an arid area. Science of the Total Environment, 2019, 680: 124-131.

[13] Liu J J, Sui Y Y, Yu Z H, Shi Y, Chu H Y, Jin J, Liu X B, Wang G H. High throughput sequencing analysis of biogeographical distribution of bacterial communities in the black soils of northeast China. Soil Biology and Biochemistry, 2014, 70: 113-122.

[14] Jiao S, Yang Y F, Xu Y Q, Zhang J, Lu Y H. Balance between community assembly processes mediates species coexistence in agricultural soil microbiomes across eastern China. The ISME Journal, 2020, 14: 202-216.

[15] Tecon R, Or D. Biophysical processes supporting the diversity of microbial life in soil. FEMS Microbiology Reviews, 2017, 41(5) : 599-623. 
[16] Crowther T W, Van Den Hoogen J, Wan J, Mayes M A, Keiser A D, Mo L, Averill C, Maynard D S. The global soil community and its influence on biogeochemistry. Science, 2019, 365(6455) : eaav0550.

[17] Neilson J W, Califf K, Cardona C, Copeland A, Van Treuren W, Josephson K L, Knight R, Gilbert J A, Quade J, Caporaso J G, Maier R M. Significant impacts of increasing aridity on the arid soil microbiome. mSystems, 2017, 2(3) : e00195-16.

[18] Gao Q, Yang Y F, Feng J J, Tian R M, Guo X, Ning D L, Hale L, Wang M M, Cheng J M, Wu L W, Zhao M X, Zhao J S, Wu L Y, Qin Y J, Qi Q, Liang Y T, Sun B, Chu H Y, Zhou J Z. The spatial scale dependence of diazotrophic and bacterial community assembly in paddy soil. Global Ecology and Biogeography, 2019, 28(8): 1093-1105.

[19] Jia X, Dini-Andreote F, Salles J F. Community assembly processes of the microbial rare biosphere. Trends in Microbiology, 2018, 26 ( 9) : 738- 747 .

[20] Liang Y T, Xiao X, Nuccio E E, Yuan M T, Zhang N, Xue K, Cohan F M, Zhou J Z, Sun B. Differentiation strategies of soil rare and abundant microbial taxa in response to changing climatic regimes. Environmental Microbiology, 2020, 22(4) : 1327-1340.

[21] Jiao S, Lu Y H. Soil pH and temperature regulate assembly processes of abundant and rare bacterial communities in agricultural ecosystems. Environmental Microbiology, 2020, 22(3): 1052-1065.

[22] Cui M M, Ma A Z, Qi H Y, Zhuang X L, Zhuang G Q, Zhao G H. Warmer temperature accelerates methane emissions from the Zoige wetland on the Tibetan Plateau without changing methanogenic community composition. Scientific Reports, 2015, 5: 11616.

[23] Tian J Q, Zhu Y B, Kang X M, Dong X Z, Li W, Chen H, Wang Y F. Effects of drought on the archaeal community in soil of the Zoige wetlands of the Qinghai-Tibetan plateau. European Journal of Soil Biology, 2012, 52: 84-90.

[24] Zhong Q P, Chen H, Liu L F, He Y X, Zhu D, Jiang L, Zhan W, Hu J. Water table drawdown shapes the depth-dependent variations in prokaryotic diversity and structure in Zoige peatlands. FEMS Microbiology Ecology, 2017, 93(6) : fix049.

[25] Yang G, Tian J Q, Chen H, Jiang L, Zhan W, Hu J, Zhu E X, Peng C H, Zhu Q, Zhu D, He Y X, Li M X, Dong F Q. Peatland degradation reduces methanogens and methane emissions from surface to deep soils. Ecological Indicators, 2019, 106 : 105488.

[26] Gu Y F, Bai Y, Xiang Q J, Yu X M, Zhao K, Zhang X P, Li C N, Liu S Q, Chen Q. Degradation shaped bacterial and archaeal communities with predictable taxa and their association patterns in Zoige wetland at Tibet plateau. Scientific Reports, 2018, 8(1): 3884.

[27] 何奕忻, 吴宁, 朱求安, 陈槐, 朱单, 彭长辉, 杨刚, 高永恒, 赵川. 青藏高原东北部 5000 年来气候变化与若尔盖湿地历史生态学研究进 展. 生态学报, 2014, 34(7): 1615-1625.

[28] Rodrigues J L A, Pellizari V H, Mueller R, Baek K, Jesus E D C, Paula F S, Mirza B, Hamaoui Jr G S, Tsai S M, Feigl B, Tiedje J M, Bohannan B J M, Nüsslein K. Conversion of the Amazon rainforest to agriculture results in biotic homogenization of soil bacterial communities. Proceedings of the National Academy of Sciences of the United States of America, 2013, 110(3) : 988-993.

[29] Liu S N, Wang H, Deng Y, Tian P, Wang Q K. Forest conversion induces seasonal variation in microbial $\beta$-diversity. Environmental Microbiology, $2018,20(1): 111-123$.

[30] Caporaso J G, Lauber C L, Walters W A, Berg-Lyons D, Lozupone C A, Turnbaugh P J, Fierer N, Knight R. Global patterns of 16S rRNA diversity at a depth of millions of sequences per sample. Proceedings of the National Academy of Sciences of the United States of America, 2011, $108(\mathrm{~S} 1)$ : 4516-4522.

[31] Kruskal J B. Nonmetric multidimensional scaling: a numerical method. Psychometrika, 1964, 29(2): 115-129.

[32] Clarke K R, Ainsworth M. A method of linking multivariate community structure to environmental variables. Marine Ecology Progress Series, 1993, 92: 205-219.

[33] Martiny J B H, Eisen J A, Penn K, Allison S D, Horner-Devine M C. Drivers of bacterial $\beta$-diversity depend on spatial scale. Proceedings of the National Academy of Sciences of the United States of America, 2011, 108(19): 7850-7854.

[34] Griffith D A, Peres-Neto P R. Spatial modeling in ecology : the flexibility of eigenfunction spatial analyses. Ecology, 2006,87 (10) : $2603-2613$.

[35] Delgado-Baquerizo M, Oliverio A M, Brewer T E, Benavent-González A, Eldridge D J, Bardgett R D, Maestre F T, Singh B K, Fierer N. A global atlas of the dominant bacteria found in soil. Science, 2018, 359(6373) : 320-325.

[36] Ladau J, Eloe-Fadrosh E A. Spatial, temporal, and phylogenetic scales of microbial ecology. Trends in Microbiology, 2019 , 27 (8): 662-669. 